\title{
The full cost of high-speed rail: an engineering approach
}

\author{
David Levinson ${ }^{1}$, Jean Michel Mathieu ${ }^{2}$, David Gillen ${ }^{\text {, }}$ \\ Adib Kanafani ${ }^{1}$ \\ ${ }^{1}$ Institute of Transportation Studies, Rm. 109 McLaughlin Hall, University of California \\ at Berkeley, Berkeley, CA 94720, USA \\ ${ }^{2}$ 4, Chemin de Coute, F-94500 Haloge, France
}

Received: May 1996 / Accepted in revised form: December 1996

\begin{abstract}
This paper examines the full costs, defined as the sum of private and social costs, of a high-speed rail system proposed for a corridor connecting Los Angeles and San Francisco in California. The full costs include infrastructure, fleet capital and operating expenses, the time users spend on the system, and the social costs of externalities, such as noise, pollution, and accidents. Comparing these full costs to those of other competing modes contributes to the evaluation of the feasibility of high-speed rail in the corridor. The paper concludes that high-speed rail is significantly more costly than expanding existing air service, and marginally more expensive than auto travel. This suggests that high-speed rail is better positioned to serve shorter distance markets where it competes with auto travel than longer distance markets where it substitutes for air.
\end{abstract}

\section{Introduction}

Despite the decline of passenger rail service for over a half century, the past decade has brought a renewed interest in intercity high-speed ground transportation in the United States (Vranich 1992; TRB 1991). Building on deployment in France and Japan, preliminary planning is underway to bring highspeed rail transportation to America. The operating high-speed rail (HSR) systems serve high volume, near-by, intercity markets. Examples include the Shinkansen in Japan, and the Trains à Grande Vitesse (TGV) in France, which is being extended to a Europe-wide network. Currently ten countries operate trains at speeds above $200 \mathrm{~km} / \mathrm{h}$ (JRE, 1994). Corridors considered in the United States include the north-east corridor (Boston-New York-Philadelphia-Baltimore-Washington) which is currently being improved, the Texas Triangle between Dallas, San Antonio and Houston, some in Florida serving

Correspondence to: D. Levinson (e-mail: dmlevins@uclink2.berkeley.edu) 
primarily tourist traffic, and six designated by U.S. Department of Transportation for further study: (1) Chicago to Milwaukee, St. Louis, Detroit, (2) Miami-Orlando-Tampa, (3) Washington D.C.-Richmond-Raleigh-Charlotte, (4) San Diego-Los Angeles-San-Francisco-Sacramento, (5) Eugene-PortlandSeattle-Vancouver, (6) New York-Albany-Buffalo. This study is evaluating the costs on corridor (4) between San Francisco and Los Angeles.

A number of factors have led to a reexamination of where, and in which mode, transportation investments should take place. First, and perhaps most importantly, has been the general move to place traditional government and transportation activities in a market setting. The privatization and corporatization of roads, rails, and parts of the aviation systems are good examples of this phenomenon. Second, there are the continuing fiscal pressures which economies face as nations reduce the proportion of the economy's resources which are taken by government. Third, there is increasing pressure to fully reflect the environmental, noise, congestion and safety costs in prices paid by transportation system users. Many full cost studies have been undertaken in recent years, particularly concerning highway travel, resulting in a wide range of estimates (Keeler et al. 1974; Fuller et al. 1983; Mackenzie et al. 1992; INRETS 1993; Miller and Moffet 1993; IWW/INFRAS 1995; IBI 1995; Litman 1995).

Our motivation is to ask two related questions:

- What are the private and social costs of providing intercity transportation?

- How do these costs influence the recommendation of investment in high-speed rail, as opposed to competing modes: air and highway?

After developing the full cost model for high-speed rail, and discussing the estimates of demand used for making the analysis, this paper evaluates in turn the infrastructure costs, the carrier operating and capital costs of the system, and the social costs of high-speed rail travel and the cost of time to users. Particular attention is paid to estimating the carrier costs through an optimization simulation of train operations and usage, which determines the number of required train-sets reflecting the daily temporal dynamics of usage and service schedules. In addition focus is placed on the social cost of noise. The final section combines the costs to develop a cost table for high-speed rail, for comparison with other modes. The conclusions address some broader issues about the feasibility and implications of high-speed rail.

\section{Full cost model}

An essential first step in examining transportation issues and in making sound decisions on passenger transportation is to understand the full costs of transportation, including accident costs, the cost of damage to the environment, the cost of noise, the cost of congestion and user time, and the cost of providing infrastructure. Furthermore, if cross subsidies between modes, passenger groups and regions are to be avoided and if users are to pay the full cost of providing and maintaining the transportation system, it 
is important to know what proportion of total costs users pay and what proportion is borne by others. As we have noted above there has been significant interest in the development of HSR links in parts of California, and yet there has been no research undertaken as to how such investment would compare with alternative investments in other modes of transportation. Nor has there been a complete assessment of the full costs of the different modes of transportation for intercity travel.

Sound investment in any mode of transportation must be based upon an understanding of how all costs vary with the size of the system, with usage of the system and within and across each cost component. Cost estimates can be divided into that portion which the user is paying, and that portion which is borne by others in the system on different routes or through general taxes. It can also be determined how much of a cost society incurs as a consequence of externalities that are generated by the different modes of transportation but not included in the price. Such a compilation would also illustrate the shift in financial burden which would take place if charges were to be levied for air, water or noise pollution.

Our objectives in the study are to estimate the full long run cost of providing intercity passenger transportation services by high-speed rail, and compare that with competing highway and air modes. The cost calculation is to include the cost of building, operating, and maintaining infrastructure, as well as carrier, user and social costs. Social costs include noise and air pollution, safety or accident costs and congestion costs. User costs include both the cost of purchasing, maintaining and operating a vehicle such as a car, but also the cost of travel time.

We begin by developing a taxonomy for representing the full costs of transportation, independent of mode:

Infrastructure costs - including capital costs of construction and debt service (ICC), and costs of maintenance and operating costs as well as service costs to government or private sector (IOC).

Carrier costs - aggregate of all fares and tariffs paid by carriers in capital costs to purchase a vehicle fleet (CCC), and maintain and operate a vehicle fleet (COC), minus those costs (such as usage charges) which are transfers to infrastructure, which we label Carrier transfers (CT).

User money costs - aggregate of all fees, fares and tariffs paid by users in capital costs (UCC) to purchase, a vehicle and money spent to maintain and operate a vehicle or to ride on a carrier (UOC); minus those costs (such as fares) which are transfers to carriers or infrastructure, which we label user transfers (UT).

User travel time costs (UTC) - the amount of time spent traveling on a mode under uncongested conditions multiplied by the monetary value of time of uncongested time.

User delay costs (UDC) - the amount of time spent traveling on a mode under congested conditions minus the amount of time spent traveling in uncongested conditions multiplied by the monetary value of time of congested time. 
Social costs - additional net external costs to society due to emissions (SEC), accidents (SAC), and noise (SNC) and are true resource costs used in making and using transportation services.

The method used to estimate the full cost (FC) of high-speed travel will combine elements from a number of sources. Adding and subtracting the above factors, thereby avoiding double-counting, we have the following equation, the components of which will be dealt with in turn in the paper:

$$
\begin{aligned}
\mathrm{FC}= & \mathrm{ICC}+\mathrm{IOC}+\mathrm{CCC}+\mathrm{COC}-\mathrm{CT}+\mathrm{UCC}+\mathrm{UOC}-\mathrm{UT} \\
& +\mathrm{UTC}+\mathrm{UDC}+\mathrm{SEC}+\mathrm{SNC}+\mathrm{SAC}
\end{aligned}
$$

Each of these costs is a function of various parameters, and depends on the level of traffic. Thus the full cost in many ways depends upon the usage. Where possible, this paper provides both the estimate of costs as a function of usage, and a range of point estimates based upon assumptions of usage and other factors.

\section{Demand forecasts}

This research employed demand forecasts for the California Corridor (Leavitt et al. 1993; Vaca et al. 1994). Because the cost estimates are integrally related to demand, some discussion of demand is warranted. The method for forecasting which provides the results reported here was based on growing existing air and highway ridership to the year 2010, and then apportioning the trips between the three modes, including the new mode of highspeed rail, air and highway, based on a logit mode choice model.

The logit model structure selected was a multinomial choice model with three choices representing the three modes. The factors considered were (1) access, egress and terminal time for air and high-speed rail, (2) travel time by each mode, (3) the cost or fare of each mode, and (4) the service headway of air and rail. The coefficients for each factor were the same across modes, while the data varied by mode and origin-destination market. Detailed results are shown in an end note ${ }^{1}$.

The model was estimated on air and highway modes on the Caltrans state model 1987 networks and automobile vehicle trip tables, and the 1992 CalSpeed Air Passenger Survey. Air trips were grown at 3\% per year, which is consistent with other studies (Vaca 1994) to obtain 2010 forecasts, auto trips were forecasted by the Caltrans Statewide model. These were combined and then apportioned based on the mode choice model.

The key variables are for application of the model in 2010 with three modes are travel time, service frequency, and rail fares to be competitive with air travel, as shown in Table 1 . These result in forecasts ranging to 5.6 billion passenger-kilometers for the mainline. This study used only one of many possible demand estimates, though the general results are expected to be relatively insensitive to small variations in demand. 
Table 1. Annual 2010 HSR ridership, distance, and fares

\begin{tabular}{|c|c|c|c|c|}
\hline Market segment & Ridership & $\begin{array}{l}\text { Distance } \\
(\mathrm{km})\end{array}$ & Passenger-km & $\begin{array}{l}\text { Fares } \\
\text { (\$ US) }\end{array}$ \\
\hline $\begin{array}{l}\text { Northern California - } \\
\text { Southern California }\end{array}$ & $7,648,000$ & 677 & $5,177,696,000$ & 56 \\
\hline Fresno - Northern California & 326,000 & 291 & $94,866,000$ & 30 \\
\hline Fresno - Southern California & 635,000 & 386 & $245,110,000$ & 30 \\
\hline Bakersfield - Northern California & 121,000 & 462 & $55,902,000$ & 40 \\
\hline Bakersfield - Southern California & 371,000 & 215 & $79,765,000$ & 25 \\
\hline Total & $10,555,000$ & & $5,653,339,000$ & \\
\hline
\end{tabular}

Source: Leavitt et al. 1993 (IURD \#609) Tables 1.2, 4.1

Note: One-way fares, distances, trips per year

\section{Infrastructure costs}

The 677 km Los Angeles-San Francisco high-speed line would link Union Station in downtown Los Angeles to a new Transbay Terminal in downtown San Francisco. While the exact alignment for the route is under study, one alignment, shown in Fig. 1, was selected for analysis. This route runs through Palmdale, the Tehachapi mountains, the Central Valley, serving Ba-

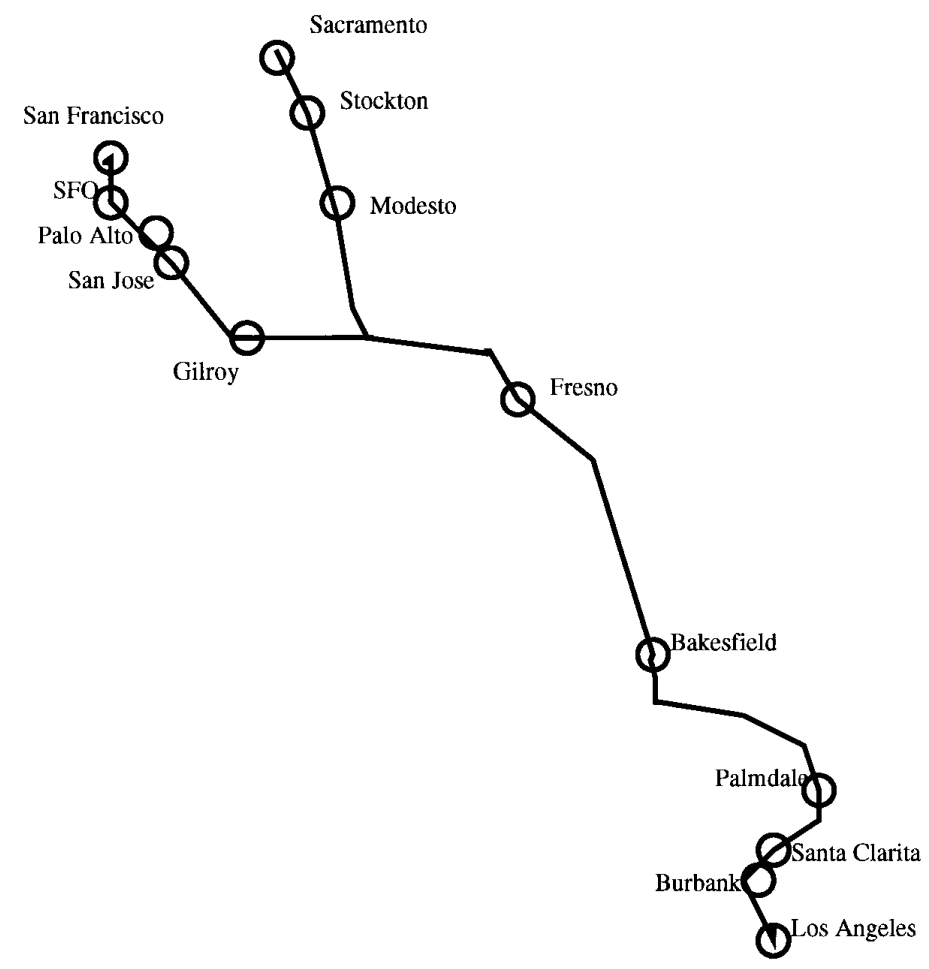

Fig. 1. Map of Central Valley Route 
kersfield and Fresno, the Pacheco Pass and the Santa Clara Valley, serving San Jose and the San Francisco Peninsula.

The cost of building the new infrastructure has been estimated to $\$ 9.6$ billion as shown in Table 2 using methodology outlined in Leavitt et al. (1992a). Briefly, the methodology estimates for each segment the detailed cost of earthworks, structures, buildings, rail, power and signals, and rightof-way. While the cost per kilometer through the Central Valley is less than \$ 6 million, construction costs through the urban segments and mountain passes are significantly higher, averaging $\$ 19$ to $\$ 30$ million per $\mathrm{km}$ (Leavitt et al. 1994). The average cost for the Los Angeles-San Francisco new high-speed line is $\$ 14$ million per $\mathrm{km}$. Assuming an opportunity cost of capital of $7.5 \%$, the annual capital cost of the alignment is $\$ 719.8$ million (or just over $\$ 1$ million per $\mathrm{km}$ ). ${ }^{2}$ The $7.5 \%$ cost is typical of current market interest rates, though other values are tested in end note 2.

To compare the California numbers with high-speed lines built or to be built in France, Table 3 shows the average infrastructure cost per kilometer for the South-East, Atlantic, Mediterranean and East TGVs. The infrastructure costs on a per kilometer basis for the South-East TGV and the Atlantic TGV are comparable to, though lower than, the estimated per kilometer cost of the high-speed line in California's Central Valley. Construction costs for the Mediterranean TGV and the East TGV are closer to the aver-

Table 2. Los Angeles-San Francisco high-speed line infrastructure cost

\begin{tabular}{|c|c|c|c|c|c|}
\hline Segment & $\begin{array}{l}\text { Distanc } \\
(\mathrm{km})\end{array}$ & $\begin{array}{l}\text { Cost } \\
\text { (US \$ ) }\end{array}$ & $\begin{array}{l}\text { Cost per km } \\
\text { (US \$) }\end{array}$ & $\begin{array}{l}\text { Travel } \\
\text { time } \\
(\min )\end{array}$ & $\begin{array}{l}\text { Travel } \\
\text { speed } \\
(\mathrm{kph})\end{array}$ \\
\hline Los Angeles Basin & 38.8 & $\$ 742,000,000$ & $\$ 19,100,000$ & 17.2 & 135 \\
\hline Techachapi Mnt. via Palmdale & 1362 & $\$ 2,760,000,000$ & $\$ 20,260,000$ & 27.6 & 296 \\
\hline Central Valley & 324.7 & $\$ 2,010,000,000$ & $\$ 6,190,000$ & 61.5 & 317 \\
\hline Pacheco Pass-Gilroy & 53.8 & $\$ 1,590,000,000$ & $\$ 29,550,000$ & 10.3 & 313 \\
\hline Gilroy-San Jose & 45.9 & $\$ 531,000,000$ & $\$ 11,570,000$ & 18.0 & 153 \\
\hline San Jose-San Francisco & 77.6 & $\$ 1,964,000,000$ & $\$ 25,310,000$ & 385 & 121 \\
\hline Total & 677.0 & $\$ 9,597,000,000$ & $\$ 14,180,000$ & 173.1 & 234 \\
\hline
\end{tabular}

Source: Leavitt et al. (IURD \#612) 1994, Table 3.1.3, p.74 (Central Valley route alternative) Note: Central Valley includes cost for 41-km Fresno Loop.

Table 3. French TGV infrastructure costs

\begin{tabular}{lcll}
\hline Route & $\begin{array}{l}\text { Distance } \\
(\mathrm{km})\end{array}$ & $\begin{array}{l}\text { Cost } \\
(\mathrm{US} \$)\end{array}$ & $\begin{array}{l}\text { Cost per km } \\
(\mathrm{US} \$)\end{array}$ \\
\hline South-East & 1004 & $\$ 2,058,000,000$ & $\$ 2,049,000$ \\
Atlantic & 726 & $\$ 1,724,000,000$ & $\$ 2,375,000$ \\
Mediterranean & 800 & $\$ 4,047,000,000$ & $\$ 5,058,000$ \\
East & 1080 & $\$ 4,371,000,000$ & $\$ 4,047,000$ \\
Total & 3610 & $\$ 12,200,000,000$ & $\$ 3,380,000$ \\
\hline
\end{tabular}

Source: SNCF, Note: in millions of 1994 US Dollars 
age cost per kilometer of the Los Angeles-San Francisco line including the urban segments and mountain passes. Aside from the general differences in land and construction costs, there has been inflation over time between the dates when the French and California systems are constructed. Like California, the higher cost of the Mediterranean TGV and East TGV is due to their more urbanized or mountainous areas.

The average infrastructure cost per passenger is simply the annual capital cost divided by the number of passengers, and thus declines with increases in passengers. Dividing the total infrastructure cost estimate of $\$ 719.8$ million per year by the estimate of 5.6 billion passenger-kilometers per year, gives an estimate of the capital cost of infrastructure of $\$ 0.129 / \mathrm{pkt}$.

\section{Carrier costs}

Our model for estimating carrier costs is divided into two components. The first is the carrier operating cost, which is found by multiplying operating cost per unit by the number of operating train units. The second is carrier capital cost, which is obtained by multiplying the unit vehicle cost by the number of operating train units. Because of the absence of data on highspeed rail operating costs in the United States, unit costs from the French TGV were used as a baseline. The number of operating units (trains) required depends on the amount and pattern of demand. A train use simulation model, SIMEX, developed for the French railway, and a model which allocates demand temporally across the day and week (MATISSE), were extended and applied to the California corridor.

\section{Simulating the number of operating units}

In order to estimate the total operating cost of the Los Angeles-San Francisco high-speed rail system, the number of train-kilometers and trainsetkilometers as well as the number of train-hours and trainset-hours must be calculated. A priori, those quantities cannot be expressed by a simple algebraic function of the level of travel demand since they depend upon numerous factors such as the fluctuations of the demand within the day and the week for every origin-destination (OD) considered in the studied network as well as the schedules, the capacity of the trainsets and the stopping pattern (the sequence of stations served by a same train) of the different services. SIMEX, designed by the French railroad, is a simulation program which translates the level of travel demand to the number of train(set)-kilometers and train(set)-hours. SIMEX enables one to measure and optimize operating cost for a given set of OD markets, providing a very detailed estimate of the operating cost and the number of trainsets required to supply services. It also provides the optimal train schedules and the expected mean load factor and revenue for each train.

In the SIMEX simulation program, the travel demand by time of day is previously estimated. The model requires estimates of passengers' time tar- 
gets within the day as well as the variation of the total demand within the week. SIMEX considers four time target distributions depending on the travel time of the OD market being, based on the actual fluctuations of the demand, observed for four French domestic OD markets: Paris-Le Mans (50 min), Paris-Lyon (2 h), Paris-Bordeaux ( $3 \mathrm{~h})$ and Paris-Marseilles $(4 \mathrm{~h}$ and $40 \mathrm{~min}$ ). Those distributions vary whether the program is run for a random weekday or a weekly peak day (such as Friday evening or Sunday evening). The time target distributions are expressed in terms of hourly percentage of the daily demand. Every OD market is characterized by a travel time and the corresponding time target distribution.

Obviously, supply characteristics affect the travel demand. Thus, the optimal supply proposed by SIMEX must be consistent with the volume of travel demand on which the simulation is based. An algorithm, in which the model for temporal allocation of demand (a variation of the French MATISSE model) and the SIMEX simulation program are sequentially used, is run until the optimal supply proposed by SIMEX corresponds to the level of demand during that time of day predicted by MATISSE. The simulation program developed for the Californian corridor is based on a similar approach, using Calspeed travel demand estimates, summarized in Table 4.

For the model we have defined two classes of train service: non-stop and local. Non-stop service connects the primary market: Los Angeles to San Francisco, while local service connects those cities along with the secondary market of trips from and to Bakersfield, Fresno and San Jose. The travel time between Los Angeles and San Francisco is $2 \mathrm{~h}$ and $53 \mathrm{~min}$ according to Table 7 . Every station is characterized by a $10 \mathrm{~min}$ stopping time. The 10 min exceeds the actual time the train stops at the station in order to account for the delay due to deceleration and re-acceleration. Assuming three stops, the Los Angeles-San Francisco local train travel time is $3 \mathrm{~h}$ and $23 \mathrm{~min}$. (Not all stations will necessarily be served on all local trains, but San Jose, Fresno, and Bakersfield are the largest markets most likely to be served. If other stations are served as well, local service is longer still and less likely to attract any non-stop traffic.)

We assume the trainsets used for the Los Angeles-San Francisco highspeed line to have 350 seats. However, the design for the system on average assumes some slack to allow for peaking, for instance seasonal variation in demand, and also must accommodate the day to day random variance. Therefore the design factor load on a segment must be less than $90 \%$ of maximum capacity so that the number of available seats will be high enough to take into account the normal daily fluctuations of demand. Finally, the mean daily factor load for both local and non-stop services must be greater than $65 \%$ of maximum capacity.

The modeling process consists of several components. The first is the estimation of service attractiveness, then non-stop and local services are scheduled respectively. 
Service attractiveness. The measure of service attractiveness compares local and non-stop trains for individuals with a choice between the two. Clearly individuals choose when to depart based on their desired arrival time and the expected travel time. Because departure and arrival times are equivalent if travel time is known, in this analysis we use the desired departure time for comparison. For instance, an individual with a desired departure time between a local and a non-stop train will compare the schedule delay against the longer travel time of a local train.

A passenger traveling between Los Angeles and San Francisco will choose the local if it provides the lowest total travel time, taking into account the schedule delay. Therefore, a passenger whose time target is $\mathrm{S}$ will choose the local train if:

$$
\mathrm{TT}_{\mathrm{ns}}+\delta(\mathrm{A} / 2+\mathrm{x}(S)) \geq T T_{l o c}+\delta(A / 2-x(S))
$$

where:

$\mathrm{TT}_{\text {loc }}=$ local service travel time

$\mathrm{TT}_{\mathrm{ns}}=$ non-stop service travel time

$\delta \quad=$ schedule delay weighting coefficient

$\mathrm{S}=$ time target

A $=$ average time between two services (it is assumed that $A$ is greater than $\Delta T T / \delta$ )

$\mathrm{x}(\mathrm{S})=$ time between clock time of previous train $+A / 2$, and desired clock time target $(S)$.

Thus for every moment on the clock which an individual might have as his time target, that individual will have to choose the previous or next train. If the trains are both non-stop or both local, the choice is simply the train nearest the time target (assuming indifference to arriving early or late), however if one is non-stop and one is local, the choice becomes more complicated.

Given a choice between two local trains ( 1 and 2 ), a passenger will choose local 1 rather than local 2 if his time target is closer to the time of departure (arrival) of local 1 . The average period of time during which local 1 is expected to attract passengers can be localted as:

$$
\Pi=\mathrm{A}-\Delta \mathrm{TT} / 2 \delta .
$$

In the case where the choice is between a non-stop and a local train, the period of time which the local train dominates is given by:

$$
\Pi=\mathrm{A}-\Delta \mathrm{TT} / \delta .
$$

The next step is to estimate the probability that a train is non-stop or local. A local train can be scheduled between two other local services (with a probability $P^{0}$ ), between a non-stop train and a local service (with a probability $P^{1}$ ) and between two non-stop services (with a probability $P^{2}$ ). Let $N$ be the total number of train trips from Los Angeles to San Francisco, and $N_{l o c}$ and $N_{n s}$ the number of local and non-stop trips from Los Angeles to San Francisco, respectively. We have: 


$$
\begin{aligned}
& \mathrm{P}^{0}=\frac{\left(\mathrm{N}_{\mathrm{loc}}-1\right)\left(\mathrm{N}_{\mathrm{loc}}-2\right)}{(\mathrm{N}-1)(\mathrm{N}-2)} \\
& \mathrm{P}^{1}=2 \frac{\left(\mathrm{N}_{\mathrm{loc}}-1\right) \mathrm{N}_{\mathrm{ns}}}{(\mathrm{N}-1)(\mathrm{N}-2)} \\
& \mathrm{P}^{2}=\frac{\mathrm{N}_{\mathrm{ns}}\left(\mathrm{N}_{\mathrm{ns}}-1\right)}{(\mathrm{N}-1)(\mathrm{N}-2)} .
\end{aligned}
$$

The average period of time during which a local service is expected to attract passengers who have a choice can be expressed as follows:

$$
\mathrm{E}\left[\Pi_{\mathrm{loc}}\right]=\mathrm{P}^{0} \mathrm{~A}+\mathrm{P}^{1}\left(\mathrm{~A}-\frac{\Delta \mathrm{TT}}{2 \delta}\right)+\mathrm{P}^{2}\left(\mathrm{~A}-\frac{\Delta \mathrm{TT}}{\delta}\right)
$$

Because in the peak period trains may come at a frequency much shorter than the difference in travel times, a similar exercise can be undertaken which looks not only at adjacent trains being local or non-stop, but also two trains away.

The total number of train departures from Los Angeles to San Francisco retained for the simulation is 54. Confining demand to be between 5 a.m. and 12 midnight, it turns out that the average period of time between two trains is $A=21 \mathrm{~min}$. We further assume that the schedule delay is less valued by passengers as on-board travel time, and assume that $\delta=0.75$. Since nonstop services are $30 \mathrm{~min}$ faster than local services, $n$ is equal to 1 .

Table 4 indicates the average period of time during which a local service is expected to attract passengers for a given level of frequency of local services. The proportion of Los Angeles-San Francisco passengers expected to travel by local trains depends upon this period of time. As stated before, just over 24 train departures are already required to carry the travel demand on secondary markets. Additional local services must be provided in order to carry the Los Angeles-San Francisco passengers expected to choose local trains.

Table 4. Number of local services required for a total number of 54 Los Angeles-San Francisco train departures

\begin{tabular}{lllllllll}
\hline$N_{\text {loc }}$ & $N_{n s}$ & $P^{0}$ & $P^{1}$ & $P^{2}$ & $E[P]$ & $\begin{array}{l}\text { LA-SFO } \\
\text { demand }\end{array}$ & $\begin{array}{l}\text { Total travel } \\
\text { demand }\end{array}$ & $\begin{array}{l}\text { Number of } \\
\text { local services } \\
\text { required }\end{array}$ \\
\hline 24 & 30 & 0.03 & 0.09 & 0.06 & 2 & 304 & 6671 & 25.42 \\
25 & 29 & 0.04 & 0.10 & 0.06 & 2 & 359 & 6726 & 25.62 \\
26 & 28 & 0.04 & 0.11 & 0.06 & 2 & 420 & 6787 & 25.86 \\
27 & 27 & 0.05 & 0.12 & 0.06 & 3 & 489 & 6856 & 26.12 \\
28 & 26 & 0.06 & 0.13 & 0.06 & 3 & 566 & 6933 & 26.41 \\
29 & 25 & 0.07 & 0.14 & 0.06 & 3 & 651 & 7018 & 26.74 \\
30 & 24 & 0.08 & 0.15 & 0.06 & 4 & 746 & 7113 & 27.10 \\
\hline
\end{tabular}


The minimum required number of local trains must be such that the total local service travel demand is less than the capacity. The minimum required number of local trains to be provided to meet the travel demand for both secondary markets and the Los Angeles-San Francisco markets is shown in Table 4, avoiding capacity constraints requires that the number of local services must be greater than 26 .

Since non-stop trains provide faster services for passengers traveling between Los Angeles and San Francisco, one would tend to maximize the number of non-stop services. Thus, the number of services suggested by the model is:

- 26 local services calling at Bakersfield, Fresno and San Jose, and

- 28 non-stop services.

The expected length of the period of time during which each local service is expected to attract passengers traveling from Los Angeles to San Francisco, $\mathrm{E}\left[\Pi_{\mathrm{loc}}\right]$, when 26 local services are provided is only $2 \mathrm{~min}$, as indicated in Table 4. The period of time during which a non-stop service is expected to attract passenger traveling between Los Angeles and San Francisco, noted $\mathrm{E}\left[\Pi_{\mathrm{ns}}\right]$, is such that:

$$
\mathrm{N}_{\mathrm{loc}} \mathrm{E}\left[\Pi_{\mathrm{loc}}\right]+\mathrm{N}_{\mathrm{ns}} \mathrm{E}\left[\Pi_{\mathrm{ns}}\right]=\mathrm{H}
$$

where:

$\mathrm{N}_{\text {loc }}=$ number of local services

$\mathrm{N}_{\mathrm{ns}}=$ number of non-stop services

$\mathrm{H}=$ total period during the day in which there is a transport demand.

According to (9) and assuming that there is a transport demand between 5 a.m. and 12 a.m., the period of time during which a particular non-stop train is expected to attract passengers is $39 \mathrm{~min}$. Secondary OD markets are served by 26 trains. Thus, the period of time during which an individual local train is expected to attract secondary market passengers is $44 \mathrm{~min}$.

For most trips, users traveling between the cities of Los Angeles and San Francisco will choose non-stops, while all those traveling in the secondary markets will use local trains. This indicates that, while there are some economies on the use of track, there is little in the way of economies of density (serving multiple markets) on the trains themselves, particularly during the peak, when choices are available.

Non-stop service scheduling process. During off peak hours, the total demand for a local train, serving all the secondary OD markets as well as the Los Angeles-San Francisco market, may be high enough to provide a viable service, whereas the travel demand for a non-stop service only serving a single OD market may be too low. During peak periods, though, the disparity of the demand among the different segments of the new line, as shown in Fig. 2, is likely to yield empty seats on the less heavily trafficked segments. To illustrate, suppose that the Los Angeles-Bakersfield travel demand for a train leaving at 6.00 a.m. is so high that many passengers willing to travel beyond Bakersfield cannot get a seat. The factor load is likely 


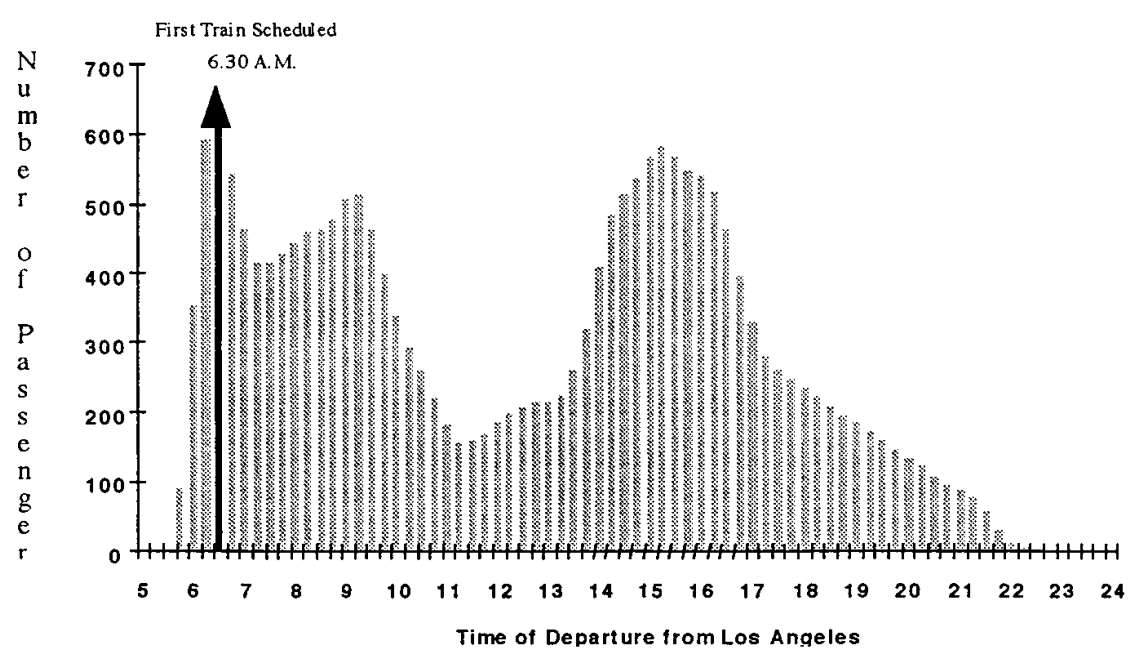

Fig. 2. Expected travel demand for non-stop services depending on the time of departure of the trains

to be low on the Bakersfield-Fresno segment if the number of passengers expected to get on the train in Bakersfield is negligible compared to the number of those who get off at this station.

Therefore, non-stop services should first be scheduled during peak hours so that the Los Angeles-San Francisco travel demand will be high enough to viably provide such a service. In addition, this is expected to smooth the demand allocated to local services and, thus, alleviate the problem of the disparity of the traffic volume expected on the different segments of the new line.

The non-stop service scheduling methodology used in the simulation program is pictured in Fig. 2. The first non-stop service is scheduled at the time when the travel demand between Los Angeles and San Francisco is the highest. As shown in Fig. 2, a train leaving Los Angeles at 6.30 a.m. would be expected to attract the greatest number of passengers. Since the maximum load factor is $90 \%$, only 315 passengers are allocated to this train. Scheduling the 6.30 a.m. train affects the potential demand for nonstop services leaving Los Angeles between 6.00 a.m. and 7.00 a.m. The new demand profile leads us to schedule the next train at $3.15 \mathrm{p} . \mathrm{m}$. The remaining demand after scheduling the 6.30 a.m. and the 3.15 p.m. trains leads us to schedule the next trains at 4.00 p.m., 2.30 p.m. and 9.15 a.m.. The same methodology is used to schedule the remaining Los Angeles-San Francisco non-stop services. If the factor load of a non-stop service is less than $20 \%$, the program stops the non-stop scheduling process. Since the travel demand is assumed to be symmetric, the non-stop service scheduling process from San Francisco to Los Angeles leads to similar schedules and revenues. The model calculates total revenue for non-stop services to be $\$ 392,000$ per day and per direction and an average factor load for nonstop services of $71 \%$. 
Local service scheduling process. The local service scheduling process is somewhat more complex than non-stop scheduling since it is directly based on the maximization of revenue rather than maximizing the number of passengers attracted by a given service. While non-stop service revenue is proportional to the number of passengers carried, the travel demand potentially attracted by a given local service corresponds to different OD markets and, thus, different fares. Moreover, the disparity of the demand in the different segments of the new line is likely to yield empty seats on the less heavily traveled segments. Thus, the local service which leads to the highest revenue does not necessarily correspond to the one which attracts the greatest number of passengers.

Every fifteen minutes, from 5 a.m. to 12 a.m., the potential demand for a local service is calculated. If the potential demand for a given local service on the most heavily traveled segment exceeds $90 \%$ of the capacity, the demand on this segment is truncated and reallocated so the composition of the travel demand according to the different OD markets remains the same.

The Los Angeles-San Francisco travel demand is allocated to the different local services assuming that the average period of time during which a local train is expected to attract Los Angeles-San Francisco passengers is $2 \mathrm{~min}$ as discussed earlier. Thus, the conditional probability that a local train attracts Los Angeles-San Francisco passengers knowing the non-stop schedules is not taken into account at this stage of the simulation.

Then, knowing the composition of the demand according to the different OD markets, it is possible to calculate the expected revenue for the studied service.

Although the travel demand is assumed to be symmetric, the local service scheduling process is likely to yield different schedules and revenues. To illustrate, a train leaving Los Angeles at 8.30 a.m. will attract passengers from Los Angeles to San Jose and San Francisco whose time target is close to 8.30 a.m. while an 8.30 a.m. local service from San Francisco to Los Angeles will potentially attract San Francisco-Los Angeles passengers whose time target is close to 8.30 a.m. as well as San Jose-Los Angeles passengers whose time target is close to 8.57 a.m. (an 8.30 a.m. San Francisco-Los Angeles local service would leave San Jose at 8.57 a.m.). The final calculations result in total revenue for local services for both directions of US \$584,136. The remaining, unallocated demand, about 9\% of Los Angeles to San Francisco demand, is then allocated to local trains where excess capacity remains.

\section{Carrier operating and vehicle cost estimates}

This section reports estimates of carrier operating costs as well as the costs per vehicle. A study conducted by INRETS and INTRAPLAN (1994) provided estimates of the average high-speed rail operating cost for Europe. In this study, operating costs were divided into the categories of sales and administration, shunting, train operations, maintenance of way and equipment, and energy. 
Sales and administration costs include labor costs for ticket sales and for providing information at the railroad stations. They also include costs for automated ticketing machine and travel agency commissions. In the INRETS/INTRAPLAN study, sales and administration costs have not been estimated on the basis of the required number of staff and automated ticketing machine for a given level of expected traffic volume but have been assumed to represent $10 \%$ of the passenger revenue.

Shunting, or track-switching, costs depend on the distance between the depot and the station as well as the average period of time trainsets stay at the depot. Nonetheless, to simplify, shunting costs could be approximated on a per train basis. The study conducted by INRETS/INTRAPLAN has shown that the cost of labor represents $80 \%$ of the total shunting cost.

Train operations can be divided into four activities: train servicing, driving, operations and safety on high-speed lines, and operations and safety on conventional lines. Train operating costs consist exclusively of labor costs. Train servicing and driving for the South-East TGV and the Atlantic TGV requires two train companions per trainset and one driver per train (which may include one or two trainsets). Operations and safety on either highspeed or conventional lines can be estimated on a per train basis.

The cost of the maintenance of electric traction installations and catenary depends on the number of trains running on the infrastructure whereas the cost of maintaining the tracks depends on the number of trainsets. Theoretically, the cost of maintenance of equipment is dependent upon the distance run by every trainset as well as the duration of use. In the INRETS/ INTRAPLAN study, the impact of the duration of use has been ignored so that maintenance of equipment cost can be estimated on a trainset per kilometer basis. According to the INRETS/INTRAPLAN study, the proportions of the cost of labor in the maintenance costs are $55 \%$ for maintenance of electric traction installations, $45 \%$ for maintenance of tracks and $50 \%$ for maintenance of equipment.

Costs can be estimated from the average consumption of energy required per kilometer which characterized the trainsets. The cost of energy is assumed to take into account the cost of transport and the electrical losses between the power generating station and the substations. Operating costs related to energy do not include any labor cost. Table 5 gives the average energy consumption for the South-East TGV and the Atlantic TGV running the new infrastructure and upgraded lines, respectively, at a load factor of $65 \%$. Energy consumption per passenger varies with the speed and increases rapidly when the speed is over $300 \mathrm{kph}$ (Pavaux 1991).

Table 6 presents the average costs used in this study. These were adopted from estimates for high-speed rail in Europe developed by INRETS/INTRAPLAN (1994), which have been used by the French Railroad to estimate operating costs for future planned TGV lines. Average operating costs are expected to differ between California and Europe, especially when labor cost represents a significant percentage of the total average cost. However, since there is no currently operating high-speed rail system in California or elsewhere in the United States, it is difficult to estimate 
Table 5. Energy consumption of the South-East and the Atlantic TGV

\begin{tabular}{llllc}
\hline Unit & $\begin{array}{l}\text { South-East } \\
\text { upgraded line }\end{array}$ & $\begin{array}{l}\text { South-East } \\
\text { new line }\end{array}$ & $\begin{array}{l}\text { Atlantic } \\
\text { upgraded line }\end{array}$ & $\begin{array}{l}\text { Atlantic } \\
\text { new line }\end{array}$ \\
\hline Kwh/km per trainset & 10.5 & 16.5 & 12 & 20 \\
Kwh/pax/100 km & 4.4 & 6.9 & 3.8 & 6.3 \\
GOE/PK & 10.3 & 16.2 & 8.95 & 14.9 \\
GOE/RPK (ortho) & 13.9 & 19.4 & 12.1 & 17.9 \\
\hline
\end{tabular}

Source: Pavaux - ITA (1991), Leavitt et al. (1992)

Note: the capacities of the trainsets used for these calculations are the following: 368 seats for the South-East TGV and 485 for the Atlantic TGV. Again the load factor is 65\%.; $\mathrm{GOE}=$ Grams of Oil Equivalent. Conversion coefficient: $1 \mathrm{Kwh}=235 \mathrm{GOE}$. This is the coefficient used by SNCF which takes into account electrical losses between the power generating station and the substations; (ortho) indicates calculated for orthodromic distances, assuming that the average ratio between the actual distances on new lines and the orthodromic distance to be 1.2 on new lines and 1.35 on upgraded lines.

Table 6. Carrier operating and capital costs for Los Angeles-San Francisco network

\begin{tabular}{|c|c|c|c|c|}
\hline Operating cost component & Units & Average cost & Quantity & Cost \\
\hline 1. Sales and administration & passengers & $\$ 5.00$ & $10,555,000$ & $\$ 52,775,000$ \\
\hline 2. Shunting & train & $\$ 87.80$ & 39,055 & $\$ \quad 3,429,029$ \\
\hline \multicolumn{5}{|l|}{ 3. Train operations } \\
\hline Train servicing & trainset-hour & $\$ 92.20$ & 120,523 & $\$ 11,112,221$ \\
\hline Driving & train-hour & $\$ 81.80$ & 119,312 & $\$ \quad 9,759,756$ \\
\hline Operations/safety on lines & train-km & $\$ 0.05$ & $27,398,020$ & $\$ \quad 1,315,105$ \\
\hline \multicolumn{5}{|l|}{ 4. Energy } \\
\hline Energy on lines & trainset-km & $\$ 2.50$ & $27,654,076$ & $\$ 69,135,190$ \\
\hline \multicolumn{5}{|l|}{ 5. Maintenance of way } \\
\hline Electric traction & train-km & $\$ 0.19$ & $27,398,020$ & $\$ \quad 5,205,624$ \\
\hline Others MOW costs & trainset-km & $\$ 1.78$ & $27,654,076$ & $\$ 49,224,255$ \\
\hline 6. Maintenance of equipment & trainset-km & $\$ 2.83$ & $27,654,076$ & $\$ 78,261,035$ \\
\hline Total operating cost $(1 \rightarrow 6)$ & & & & $\$ 280,217,215$ \\
\hline Total passenger revenue & & & & $\$ 499,087,130$ \\
\hline GROSS OPERATING & & & & $\$ 218,869,915$ \\
\hline \multicolumn{5}{|l|}{ SURPLUS } \\
\hline \multicolumn{5}{|l|}{ Capital cost of rolling stock } \\
\hline $\begin{array}{l}\text { Sales tax, interest and } \\
\text { depreciation of rolling stock }\end{array}$ & trainset & $\$ 2,123,167$ & 42 & $\$ 89,173,017$ \\
\hline GROSS MARGIN & & & & $\$ 129,696,898$ \\
\hline Infrastructure costs & fixed & $\begin{array}{l}\$ 9,597 \\
\text { Million }\end{array}$ & $7.5 \%$ & \$719.8 Million \\
\hline $\begin{array}{l}\text { NET CONTRIBUTION } \\
\text { (SUBSIDY) }\end{array}$ & & & & \$ 590.1 Million \\
\hline
\end{tabular}

Note: Average costs in 1994 US \$ as estimated in the INRETS/INTRAPLAN (1994) Study, except energy and sales and administration, as noted in text. See End note 1 for discussion of various interest rates. 
specific average costs for California. Thus, INRETS/INTRAPLAN estimates are used to forecast the operating cost of high-speed rail in California except for energy and sales and administration costs.

Sales and administration costs are dependent on the required number of staff and automated ticketing machine for a given level of expected traffic volume. Assuming that they represent $10 \%$ of the passenger revenue in $\mathrm{Ca}-$ lifornia would imply that the revenue per passenger would be comparable to those observed in Europe. Thus, it may be more accurate to estimate sales and administration costs on a per passenger basis rather than revenue. As a first approximation, sales and administration costs in California will be assumed to be $\$ 5$ per passenger.

The unit cost rate for electrical power pricing in this analysis will be assumed to be $\$ 0.10$ per kilowatt-hour, implicitly assuming full cost pricing within the electrical generation sector. According to Table 5, the energy consumption of an Atlantic TGV trainset cruising at 300 kilometers per hour on the new high-speed line is $20 \mathrm{kwh}$ per kilometer. The maximum speed on the California high-speed line has been assumed to be $320 \mathrm{kph}$, as shown in Table 1. Moreover, the average number of train stops on the new line is expected to be higher. Thus, the energy consumption on the new line for California will be assumed to be $25 \mathrm{kwh}$ per kilometer and per trainset.

The simulation estimates the expected number of passengers carried per train as well as the number of train or trainset-kilometers and train or trainset-hours. It turns out that 108 train-set departures per day are required for the Los Angeles-San Francisco corridor (54 in each direction). Assuming that a train must stay at least one hour at the destination station before being available to head out once again for a new service, the required number of trainsets is 40 . This minimum number is usually increased by $5 \%$ in order to take into account the proportion of the total fleet unusable due to defect or maintenance. Thus the total number of trainsets in the fleet would be 42 .

In the INRETS/INTRAPLAN study, a 350 seat capacity high-speed trainset has been estimated to cost $\$ 17,849,000$ (12 million ECU in 1991). Trainsets are depreciated over fifteen years. The general sales tax on trainsets is assumed to be 5\%, because the tax is applied to all sales transactions, and leaves the transportation sector, it is not considered a transfer here. The capital cost for the rolling stock is then to be $\$ 2,123,000$ per trainset and per year, including interest and depreciation of rolling stock as well as sales tax, calculated at a $7.5 \%$ discount rate. Multiplying 42 trainsets by $\$ 2,123,000$, and dividing by 5.6 billion passenger kilometers, gives a capital cost of rolling stock of $\$ 0.016$ per passenger kilometer.

The total operating cost for the Los Angeles-San Francisco high-speed rail system is $\$ 280$ million for 10,555,000 passengers, 5.6 billion passenger-kilometers and 9.7 billion seat-kilometers. Table 6 shows the different components of the operating cost as well as the rolling stock and infrastructure capital cost. Dividing the operating cost of $\$ 280$ million by 5.6 billion passenger-kilometers gives an average carrier operating cost of $\$ 0.050 / \mathrm{pkt}$. 


\section{User costs}

Our general model of full costs includes several categories of user costs, including user capital costs, user operating costs, user time costs, and user delay costs, as well as user transfers. Because we are dealing with a rail system, users are assumed to have no net additional capital costs, unlike a highway system. In our modeling analysis, we have excluded access costs to the high-speed rail stations, just as in the analyses of competing air and highway modes, we exclude access costs to airports and the intercity highway system, which are comparable. User operating costs are thus the fares users pay to the rail carrier, which can be considered entirely a transfer, and are thus not included in the final calculation of costs. The fares we have assumed are given in Table 1 earlier in the paper. User time and congestion is worth some discussion. The non-stop travel times between points are given in Table 7, which needs to be coupled with a 10 min stop at each station for local trains. User cost of time depends on the speed of service, the expected speed of service for the various markets analyzed is given in Table 7. We also need to assume a value of time, for exposition we take the conservative value of $\$ 10 / \mathrm{h}$, recognizing that the value of time varies widely across individuals depending on numerous factors, and that through the literature a large range is found, a summary of values of time is given in Levinson et al (1996). The resulting costs per passenger kilometer traveled are given in Table 7 . The user time cost in $\$ / p k t$ ranges from $\$ 0.03-\$ 0.08$, with the highest time cost on the trips with the slowest trains. The value of $\$ 0.04 / p k t$, found on the non-stop market from Los Angeles to San Francisco, is the one most users will experience. We are assuming that there are no congestion costs on the rail system, that trains do not delay each other.

Table 7. User time costs

\begin{tabular}{|c|c|c|c|c|c|c|}
\hline Segment & $\begin{array}{l}\text { Distance } \\
(\mathrm{km})\end{array}$ & $\begin{array}{l}\text { Average } \\
\text { running } \\
\text { speed } \\
(\mathrm{kph})\end{array}$ & $\begin{array}{l}\text { Running } \\
\text { time } \\
(\mathrm{min})\end{array}$ & $\begin{array}{l}\text { Travel } \\
\text { time } \\
(\min )\end{array}$ & $\begin{array}{l}\text { User } \\
\text { time } \\
\text { cost }\end{array}$ & $\begin{array}{l}\text { User } \\
\text { cost } \\
(\$ / p k t)\end{array}$ \\
\hline San Jose-San Francisco & 77 & 121 & 38 & 38 & $\$ 6.33$ & $\$ 0.08$ \\
\hline Bakersfield-Fresno & 171 & 317 & 32 & 32 & $\$ 5.33$ & $\$ 0.03$ \\
\hline Fresno-San Jose & 213 & 255 & 50 & 50 & $\$ 8.33$ & $\$ 0.04$ \\
\hline Los Angeles-Bakersfield & 215 & 246 & 52 & 52 & $\$ 8.66$ & $\$ 0.04$ \\
\hline Fresno - San Francisco & 291 & 198 & 88 & 98 & $\$ 16.33$ & $\$ 0.06$ \\
\hline Bakersfield - San Jose & 384 & 280 & 82 & 92 & $\$ 15.33$ & $\$ 0.04$ \\
\hline Los Angeles - Fresno & 386 & 276 & 84 & 94 & $\$ 15.67$ & $\$ 0.04$ \\
\hline Bakersfield - San Francisco & 462 & 231 & 120 & 140 & $\$ 23.33$ & $\$ 0.05$ \\
\hline Los Angeles - San Jose & 600 & 266 & 135 & 155 & $\$ 25.83$ & $\$ 0.04$ \\
\hline $\begin{array}{l}\text { Los Angeles -San Francisco } \\
\text { (non-stop) }\end{array}$ & 677 & 234 & 173 & 173 & $\$ 29.89$ & $\$ 0.04$ \\
\hline
\end{tabular}

Note: Travel time $=$ running time $+10 \mathrm{~min}$ per stop, cost $=\$ 0.167 / \mathrm{min} *$ travel time 


\section{Social costs}

In our initial model of full costs, we identified several categories of social or external costs which transportation creates, including accident costs, environmental costs, and noise costs. Our list of social costs is smaller than that proposed by some authors (DeLuchi 1991; Litman 1995), we do this to avoid double counting, rather than for any ideological reasons. What we are aiming at is a complete list of costs directly attributable to the transportation of people and goods. We have thus excluded many indirect costs, such as the change in the cost of land outside the transportation system, the cost of parking, the cost of defense etc. One reason for excluding indirect costs rests on the logic that an externality generated by production prior in the supply chain to transportation should be internalized in the price paid for that service. An example of this can be found with air pollution caused by the manufacture of steel used in cars or trains. While this pollution is indirectly attributable to transportation (the steel would not otherwise be produced), it is generated from a point source which is or can be regulated for emission levels, and those regulations may be set at the optimal level of pollution as decided by society. The costs of those regulations should be borne by those purchasing steel to manufacture cars or trains, who pass it along to the purchaser of the car or train. We count that cost in the capital cost of those goods to the final user or carrier, not as a social or external cost. A like argument applies to water pollution and wetlands mitigation, which we assume to be costs of infrastructure construction.

\section{Air pollution}

Since high-speed rail systems are electrically powered, we assume that there are no air pollution externalities caused by the rail system, and that the cost of pollution is internalized in the electricity generation sector of the economy, which results in higher energy prices than would otherwise be found. While we do not consider pollution costs, we recognize this is an issue which is under debate. Some have argued that the incremental pollution due to the increase in power requirements from the public utility which supplies power to the HSR should be included as part of the social costs of HSR, because it represents an avoidable cost. With electrically powered trainsets, the pollution from power generation is moved backwards in the supply relationship. We argue that this pollution is properly associated with the electric power generation sector, in which additional pollution costs are, or should be, internalized.

For informational purposes, Table 5 provides energy usage by the French TGV system. As a point of comparison, Hirota and Nehashi (1995) report the Shinkansen as producing 2.30 tons of $\mathrm{CO}$ per billion passenger kilometers, 0.18 tons of $\mathrm{SO}_{\mathrm{x}}$ and 0.31 tons of $\mathrm{NO}$, generated by burning $136 \mathrm{kcal}$ of energy per passenger kilometer. The economic damages caused by that energy generation depend very much on where the power plants are located. With deregulated energy markets being implemented in California 
and elsewhere, it will be very difficult to assess those economic damages, since it will be unclear who is the marginal producer or user, the energy used for the high-speed rail could be generated at any plant in the Western United States, from hydro-electric, nuclear, or coal, all with very different environmental consequences, and all subject to intense regulation.

\section{Accidents and safety}

Because of the safety rates of the existing high-speed rail systems, we will assume no risk of accident. This does not mean there is no safety cost, rather that it is incorporated in higher capital costs to design the system to be safer. These extra capital costs include the elimination of at-grade crossings with streets and highways, separation of freight and passenger traffic, and better controls.

\section{Noise}

For our analysis, the social costs of HSR are restricted to noise. Modeling the economic damage of noise pollution requires several elements. First is an estimate of noise production, second is the damage caused by noise in terms of reduced property values.

Noise production. HSR noise emanates from several sources: wheel-rail noise, which is proportional to $30 \log$ Speed; aerodynamic noise which is proportional to $60 \mathrm{log}$ Speed (Hanson 1990); and a third source due to electrification. Measurements have been made for noise levels of different high-speed train technologies, as given in Table 8. Hanson (1990) has calculated that in order to maintain $55 \mathrm{~dB}(\mathrm{~A})$ background noise level at $180 \mathrm{mph}(288 \mathrm{kph})$, one needs about a $480 \mathrm{ft}(146 \mathrm{~m})$ corridor. Our noise damage model, discussed below, requires calculating the noise as a function of speed $(V)$ in $\mathrm{kph}$, and then developing a noise exposure forecast (NEF) consistent with the number of trains used. We estimated an OLS regression model from the data in Table 8, giving the following equation ( $r$ squared $=0.81$ ).

$$
\mathrm{dB}(\mathrm{A})_{@ 25 \mathrm{~m}}=19.94+29.72 \log 0.6 \mathrm{~V}
$$

The impact of noise decays with distance. For the Shinkansen, Wayson and Bowlby (1989) report that the noise level does not decrease linearly for each doubling of distance as would be expected (probably due to ground impedance), and that geometric spreading has much more effect on the noise levels at highspeed than does changes in speed (noise levels are influenced more by distance than changes in speed). To account for a distance decay ( $\mathrm{D}$, in meters greater than 25), we estimated an OLS regression model from data provided from Matsuhisa et al. $(1989)(\mathrm{r}$-squared $=0.98)$ :

$$
\mathrm{dB}(\mathrm{A})_{@ \mathrm{D}}=\mathrm{dB}(\mathrm{A})_{@ 25 \mathrm{~m}}-6.01 \ln (\mathrm{D})
$$


Table 8. Train noise levels $(\mathrm{dB}(\mathrm{A}))$ for various technologies

\begin{tabular}{lcccc}
\hline Train & $96 \mathrm{kph}$ & $160 \mathrm{kph}$ & $192 \mathrm{kph}$ & $320 \mathrm{kph}$ \\
\hline Maglev & & 72 & 75 & 85 \\
ICE & 72 & 75 & 78 & 92 \\
Shinkansen & 79 & 80 & 82 & \\
Amtrak & 79 & 82 & 89 & 97 \\
TGV $*$ & & & \\
Turbotrain & & 100 & & \\
\hline
\end{tabular}

Source: Hanson 1990, except* from Wayson and Bowlby 1989.

Note: at $25 \mathrm{~m}$.

When performing noise-cost studies, sound, which varies over the course of time, must be averaged to give an equivalent loudness, which is the continuous energy mean equivalent of the noise level measured over a specific period. This is further translated into an index, in the United States the Noise Exposure Forecast (NEF) is used, which is defined from the effective perceived noise level (Lepn) and the number of events $(N)$ as follows (Nelson 1982):

$$
\mathrm{NEF}=\mathrm{Lepn}+10 \log _{10} \mathrm{~N}-88
$$

For our analysis, we take the effective perceived noise level to be equal to $\mathrm{dB}(\mathrm{A})_{@ \mathrm{D}}$, and the number of events $(N)$ to be the number of trains per day.

Noise damages. The damages caused by noise include the loss of sleep, lower productivity, psychological discomfort and annoyance. These are hard to quantify, but because they are associated with a place, the quantity of damage is often viewed as resulting in lower property values. A number of studies have been performed over the years to measure the decline in residential property value due to noise and its associated vibration. This has not been done for non-residential (commercial and public) buildings, however, where abatement measures are more cost-effective. Modra and Bennett (1985), Nelson (1982), and others have collected empirical findings, which are summarized in Levinson et al. (1996). These studies use a noise depreciation index (NDI) which is the percentage reduction of house price per $\mathrm{dB}(\mathrm{A})$ above some base. To determine the amount of noise damage produced by a facility, one must know the noise produced on that facility (as a function of traffic volume) and the location of residences near the facility. Also the house value must be known because the impact of noise is generally found to be a percentage reduction in house price rather than a fixed value. These property value impact studies have been performed for areas around highways and airports, though no studies were found around rails. However, the average NDI for all of the airport noise surveys since 1967 is 0.62 , the same value as for highways, giving us some confidence in using that number for as the noise depreciation index for a high-speed 
rail line. However further research should investigate the effect of high intensity noise (produced more often by trains) vs. high frequency noise (produced by cars).

Application of the noise model, under certain assumptions, gives us an average cost curve for the noise damage associated with each passenger kilometer traveled depending on the number of trains per hour $(Q t)$. We perform this analysis for two train speeds: $200 \mathrm{kph}$ and $320 \mathrm{kph}$, and under the following assumptions: a discount rate of $7.5 \%$, trains in service $18 \mathrm{~h}$ per day, each train with a capacity of 350 passengers and a $75 \%$ load factor, a noise depreciation index of 0.62 , an average home value of $\$ 250,000$ and a density of 360 household per square kilometer. The damage caused by the new service is determined by comparing the noise before and after the service is deployed, in our analysis we assume a baseline of zero background noise.

The model is solved by dividing the area on each side of the tracks into $10 \mathrm{~m}$ strips $(s)$ parallel to the tracks. Each $10 \mathrm{~m}$ by one kilometer strip has a number of housing units $\left(H_{s}\right)$ depending on the density. The total damage for each strip is computed based on multiplying the homes by the value $(H V)$ of each home by the noise depreciation index (NDI) by the net increase in the NEF [after $\left(\mathrm{NEF}_{\mathrm{a}}\right)$ - before $\left(\mathrm{NEF}_{\mathrm{b}}\right)$ ]. The total damage as a present cost $(P)$ is summed over all the $10 \mathrm{~m}$ strips for a $1 \mathrm{~km}$ stretch.

$$
\mathrm{P}=\sum_{\mathrm{s}}\left(\mathrm{H}_{\mathrm{s}}\right)(\mathrm{HV})(\mathrm{NDI})\left(\mathrm{NEF}_{\mathrm{a}}-\mathrm{NEF}_{\mathrm{b}}\right)
$$

To estimate the full cost of noise per passenger kilometer traveled, we need to convert the total change in the prices of homes as a result of noise damage into an annual charge. The total damage is then amortized over a number of years $(n)$, which we take to be 30 , of passenger travel at the assumed discount rate $(i)$ of $7.5 \%$. This charge can then be divided by the total passenger volume per year to develop the charge per passenger kilometer. We use the following capital recovery [Present Cost $(P) \rightarrow$ Annual Cost $(A)]$ equation in the model:

$$
A=P \frac{i(1+i)^{n}}{(1+i)^{n}-1}
$$

Because of the logarithmic shape of the noise curves, the higher the level of background noise, the less damage each additional unit of noise production causes. The costs are linear with respect to density, home value, noise depreciation index, and the number of passengers (as determined by capacity and load factor). It is non-linear with respect to speed and number of trains per hour. Under the assumptions identified above, social average costs of noise (SNC) are given by the following equations ( $r$-squared $=0.99,0.96$, respectively), these are graphed in Fig. 3. 
Aver age Cost of High Speed Rail Noi se

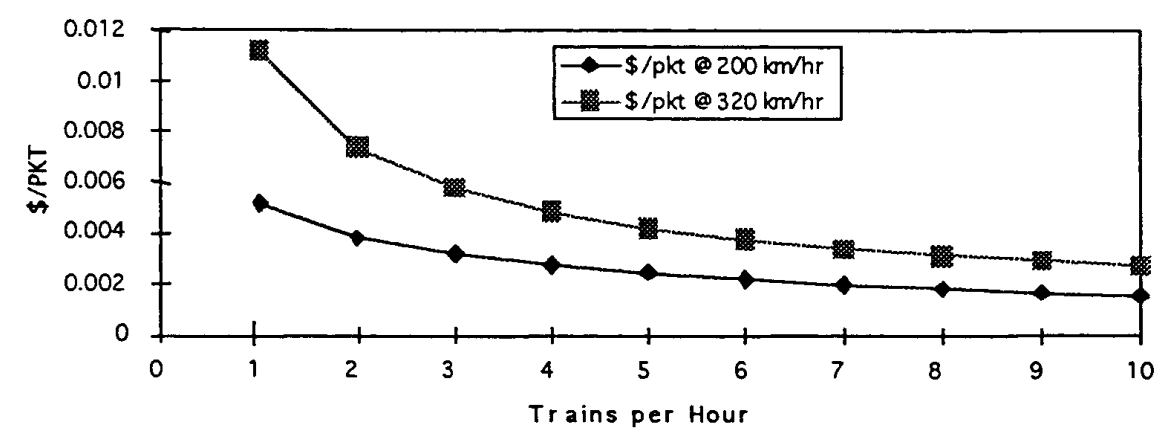

Fig. 3. Average cost of high-speed rail noise

$$
\begin{aligned}
& \mathrm{SNC}_{@ 200 \mathrm{kph}}=0.0050-0.0015 \ln (\mathrm{Qt}) \\
& \mathrm{SNC}_{@ 320 \mathrm{kph}}=0.0103-0.0035 \ln (\mathrm{Qt})
\end{aligned}
$$

At $200 \mathrm{kph}$, our best estimate of the expected cost of noise is $\$ 0.0025 / \mathrm{pkt}$; at $320 \mathrm{kph}$ it is $\$ 0.0043 / p k t$, assuming 5 trains per hour, though clearly these costs depend on local conditions as described above.

\section{Total costs and intermodal comparison}

Table 9 gives summary results of the full cost of high-speed rail per passenger kilometer for the California corridor. These costs can be compared with similar studies of other modes developed by the authors (Levinson et al. 1996). The costs per passenger kilometer traveled for other modes could be estimated based on current conditions, highway costs were based on state expenditures for infrastructure, user expenditures for owning a car, and the best estimates of current social costs. Air costs were based on allocating the cost of the air control system to current users, and a cross-sectional analysis of airport infrastructure and terminal costs, as well as estimates of current social costs.

The costs of high-speed rail are about the same as the costs for highway travel (assuming 1.5 persons per vehicle), and much higher than for air. Air is the fastest, and thus commits the users to the least time spent in travel. It requires the least infrastructure of all the modes, as airports are far less costly to build and expand than highways or high-speed rail. It also produces fewer externalities than the other modes. While there is risk of accident, it is very small. There is some congestion, though this is contained within the air travel system, and borne by air travelers. Unlike highways or high-speed rail, the noise problem is contained to points, rather than being spread over the entire corridor, and is likely to be significantly ameliorated 
Table 9. Intermodal comparison of long-run average costs

\begin{tabular}{llll}
\hline Cost category & Air system & High-speed rail & Highways \\
\hline Infrastructure: capital and operating & $\$ 0.0182$ & $\$ 0.129$ & $\$ 0.012$ \\
Carrier: capital cost (trains, planes) & $\$ 0.0606$ & $\$ 0.016$ & $\$ 0.000$ \\
Carrier: operating cost & $\$ 0.0340$ & $\$ 0.050$ & $\$ 0.000$ \\
User: capital \& operating & $\$ 0.0000$ & $\$ 0.000$ & $\$ 0.086$ \\
User: time & $\$ 0.0114$ & $\$ 0.044$ & $\$ 0.100$ \\
User: congestion & $\$ 0.0017$ & $\$ 0.000$ & $\$ 0.0046$ \\
External: accidents & $\$ 0.0004$ & $\$ 0.000$ & $\$ 0.0200$ \\
External: noise & $\$ 0.0043$ & $\$ 0.002$ & $\$ 0.0045$ \\
External: pollution & $\$ 0.0009$ & $\$ 0.000$ & $\$ 0.0031$ \\
Total & $\$ 0.131$ & $\$ 0.241$ & $\$ 0.230$
\end{tabular}

Note: \$/pkt for car assuming 1.5 passengers per car, $\$ /$ pkt for air and high-speed rail, all transfers are subtracted out. Numbers may not add exactly due to rounding error. Discount rate of capital assumed to be $7.5 \%$ throughout.

with new generations of aircraft engines. It does pollute more than highspeed rail, but less than highways.

The greater external costs generated by highway travel were compensated by lower infrastructure costs than high-speed rail. It should also be noted that many highway costs are already borne by users: accidents, and congestion, while external to the driver are internal to the highway transportation system. Also user costs of owning and maintaining a vehicle are borne by users, and do not require subsidy. Because the automobile is slower than other modes, it has the highest user time costs. However, individuals who choose to make the long drive between San Francisco and Los Angeles do so knowing it is more expensive than air travel, and probably are considering other benefits, such as the flexibility that the car offers as well as eliminating the need to rent a car at the destination end of the trip.

Given all of the uncertainty inherent in the data, our analysis provides a first order estimate of the full cost of the trip on the California corridor from Los Angeles to San Francisco $(677 \mathrm{~km})$ of $\$ 163$ per trip. Our estimates, shown in Table 6, suggest that the proposed high-speed rail system would require a public subsidy of $\$ 590,100,000$ per year to be competitive with air transportation.

It is important to understand the linkages between demand, supply, and cost. If the cost function is dominated by large fixed costs, as is the case with high-speed rail, which must be provided independent of the number of riders, then providing more riders will lower the cost to the average user. Our estimates were made based on a liberal assumption of 5.6 billion passenger miles per year, and though the precise numbers may change with changes in forecasts, the basic result will remain. It should be noted that the high-speed rail forecast was based on highly subsidized fares. It is likely that if market fares (to recover the infrastructure and carrier costs) were in place without subsidy, that the system would be unsustainable. 
In summary, high-speed rail is the costliest of the three modes we examined, largely because of its high capital costs relative to the number of anticipated riders. It has the highest costs to the service provider, presumably the state of California, because other modes spread their costs among private sector owners and operators of vehicles and parts of the infrastructure system.

\section{Conclusion}

It is doubtful that without considerable subsidy high-speed rail could be constructed, much less profitable in California. These subsidies are anticipated to be higher than those required in other countries. The conditions in Europe and Japan during the early stages of high-speed rail are significantly different than most parts of the United States. Land uses are denser and cities are closer together. Furthermore, constraints on federal spending in the 1990's hinder the development of new infrastructure. A last key distinction is that the regulated transportation sectors in Japan and Europe prevented competition from air travel to the same degree as in the United States when the HSR lines were planned and deployed. Had air travel been deregulated and privatized at the time, the decision to proceed with highspeed rail, particularly in Europe, may have been different. As an illustration of this, Southwest Airlines is a major opponent of high-speed rail in Texas (Krumm 1994). As with all rail modes, there is a significant amount of inflexibility associated with the system design. The high-speed networks are limited, and the rails require very specific vehicles. Compared with the greater flexibility afforded the untracked air travel system or the ubiquitous highway system, high-speed rail faces serious difficulties.

However, should such a system be built, it can be expected to increase the commuter sheds of both the San Francisco Bay area and Los Angeles to include Central Valley cities. A one hour commute, while on the long end of acceptable, would now be much farther away through the use of local high-speed trains. On the other hand, total travel between the two metropoles would likely increase very little, since the time and cost savings of even non-stop high-speed rail against the existing frequent air service from the three Bay area and five Los Angeles airports are minimal.

Acknowledgements. This research was funded by the California Department of Transportation, California High Speed Rail Commission, and the University of California at Berkeley Institute of Transportation Studies. We would like to thank Tom Reinhold and Dan Leavitt for comments on earlier drafts of this work. The ideas and opinions expressed in the paper are solely those of the authors and do not represent the funding institutions. 


\section{End notes}

${ }^{1}$ Estimation results for the logit demand model are given below

\begin{tabular}{llll}
\hline Coefficient & Variable & Estimate & "T" statistic \\
\hline$\beta_{1}$ & Access, egress, & -0.02729 & -57.9 \\
$\beta_{2}$ & terminal time & -0.0310 & -64.50 \\
$\beta_{3}$ & Linehaul time & -0.01835 & -24.0 \\
$\beta_{4}$ & Cost, fare & -6.99 & -17.4 \\
\hline
\end{tabular}

"Rho-squared" w.r.t. zero $=0.5393$

"Rho-squared" w.r.t. constants $=0.3850$

(Vaca et al. 1994)

${ }^{2}$ The cost of capital may differ from the assumed value of $7.5 \%$. To illustrate the following table shows the unit cost of infrastructure, rolling stock, and noise damage at different interest rates $(1 \%-10 \%)$. Infrastructure is assumed to be depreciated over an infinite time period, rolling stock over 15 years and noise damage over 30 years.

$\$ / \mathrm{pkt}$ at various interest rates

\begin{tabular}{llll}
\hline Interest rate & Infrastructure & Rolling stock+sales tax & Noise \\
\hline 0.01 & 0.0169 & 0.0100 & 0.0011 \\
0.02 & 0.0339 & 0.0108 & 0.0013 \\
0.03 & 0.0509 & 0.0116 & 0.0015 \\
0.04 & 0.0679 & 0.0125 & 0.0017 \\
0.05 & 0.0848 & 0.0134 & 0.0019 \\
0.06 & 0.1018 & 0.0143 & 0.0021 \\
0.07 & 0.1188 & 0.0152 & 0.0023 \\
0.075 & 0.1273 & 0.0157 & 0.0025 \\
0.08 & 0.1358 & 0.0162 & 0.0026 \\
0.09 & 0.1527 & 0.0172 & 0.0028 \\
0.1 & 0.1697 & 0.0183 & 0.0031 \\
\hline
\end{tabular}

1. Cost estimates for other modes were treated differently, based on annual expenditures and state bond ratings (their market interest rates) to discount their estimated capital stock in the case of highway infrastructure. To the extent that interest rates are higher or lower, they will impact modes similarly, though obviously favoring the most long-term capital intensive mode (high speed rail) more than the others.

2. Since the San Jose-San Francisco segment is a short, urban speed- restricted segment, highspeed rail may not be the best adapted service to serve this OD market. Therefore, the San Jose-San Francisco travel demand will not be taken into account when optimizing the schedules. Nonetheless, available capacity provided by local services from Los Angeles to San Francisco and vice versa may be allocated to the San Jose-San Francisco OD market.

3. These HSR forecast used in this study are based on the assumptions that stations will be built in Palo Alto, Gilroy, Burbank, Santa Clarita and Palmdale. In our example the travel demand to and from these stations will not be taken into account.

\section{References}

DeLuchi MA (1991) Emissions of Greenhouse Gases from the Use of Transportation Fuels and Electricity: Volume 1 Main Text. Department of Energy: Argonne National Laboratory, Center for Transportation Research, Energy Systems Division 
Fuller J, Hokanson B, Haugard J, Stoner J (1983) Measurements of Highway User Interference Costs and Air Pollution and Noise Damage Costs. Institute of Urban and Regional Research, University of Iowa (NS 83-817)

Hanson C (1990) High-speed Rail System Noise Assessment TRR 1255 p 119-121, W. Harris Miller Miller and Hanson, 429 Marrett Rd. Lexington, Mass 02173

Hirota R, Nehashi A (1995?) Re-evaluation of the Shinkansen: from the standpoint of energy consumption, environmental protection, and preservation of human life (working paper)

Hirota R, Nehashi A (1995) Re-evaluation of the Shinkansen: From the Standpoint of Energy Consumption, Environmental Protection and Preservation of Human Life. mimeo. Japan Railway Construction, Tokyo, Japan

IBI Group (1995) Full Cost Transportation Pricing Study for Transportation and Climate Change Collaborative. INFRAS, IWW (1995) External Effects of Transport. International Union of Railways, IWW - Karlsruhe University, INFRAS Consultants

INRETS (1993) Impact des Transport Terrestres sur L'Environment: Methodes d'evaluation et couts sociaux. Synthese Inrets No. 23 (TA 1071. A1 S9 no. 23 C.2)

INRETS/INTRAPLAN (1994) Trafic et Rentabilite du Reseau Ouest-Europeen de Trains a Grande Vitesse. Union Internationale des Chemins de Fer, Paris

Japanese Railway Engineering (1994) Special Issue: 30 Years of Progress in the Shinkansen. Japanese Railway Engineering \# 131

Keeler TE, Merewitz LA, Fisher P (1975) Full Costs of Urban Transport. University of California at Berkeley Report

Krumm BK (1994) High Speed Ground Transportation Systems: A Future Component of America's Intermodal Network? Transp Law J 22:309-326

Leavitt D, Vaca E, Hall P (1992a) High Speed Trains for California Strategic Choice. Vol. I: Comparison of Technology and Choice of Route. Institute of Urban and Regional Development (IURD) working paper \# 564, University of California at Berkeley

Leavitt D, Hall P, Vaca E (1992b) CalSpeed: High-Speed Trains For California. Vol. II: Detailed Segment Descriptions, Cost Estimates, and Travel Times Calculation. University of California Transportation Center (UCTC) working paper \#105

Leavitt D, Hall P, Vaca E (1993) Calspeed Report: Revenue and Ridership Potential in the San Francisco/Sacramento-Los Angeles Corridor. Institute of Urban and Regional Development (IURD) working paper \# 609, University of California at Berkeley

Leavitt D, Cheng P, Vaca E, Hall P (1994) Potential for Improved Intercity Passenger Rail Service in California: Study of Corridors. Institute of Urban and Regional Development (IURD) working paper \# 612, University of California at Berkeley

Levinson D, Gillen D, Kanafani A, Mathieu J-M, Reinhold T (1996) The Full Cost of Intercity Transportation: A Comparison of Air, Highway, and High Speed Rail in California. University of California at Berkeley, Institute of Transportation Studies, Research Report UCB-ITS-RR-96-3

Litman T (1995) Transportation Cost Analysis: Techniques, Estimates and Implications. Transport Policy Institute, Victoria, BC

Mackenzie J, Dower RC, Chen DDT (1992) The Going Rate: What it Really Costs to Drive World Resources Institute. Washington DC

Mathieu G (1991) New High Speed Rail Developments: France's Master Plan. SNCF, Table 7

Matsuhisa H, Zhang W, Honda Y, Sato S (1989) Vibration Reduction of a Railway Wheel by Cantilever Type Dynamic Absorbers - Optimal Adjustment of Absorber and Experiment. JSME International Journal. Series III Vibration Control Engineering for Industry. Sep. 1989. 32(3):400-405

Miller P, Moffet J (1993) The Price of Mobility: Uncovering the Hidden Costs of Transportation National Resources Defense Council

Modra JD, Bennett DW (1985) Cost-Benefit Analysis of the Application of Traffic Noise Insulation Measures to Existing Houses. Forum Papers of $10^{\text {th }}$ Australian Research Forum, Melbourne, 13-15 May 1985, Vol. 1, pp 63-86

Nelson JP (1980) Airports and Property Values: A survey of recent evidence. J Transp Econ Policy, 43

Nelson JP (1982) Highway Noise and Property Values: A survey of recent evidence. J Transp Econ Policy, 128 
Pavaux J (1991) Les Complementarities train/avion en Europe. Institut du Transport Aerien, Paris

Transportation Research Board (1991) In Pursuit of Speed: New Options for Intercity Passenger Transportation, Special Report 233. Transportation Research Board, Washington DC

Vaca E, Leavitt D, Hall P (1994) Calspeed Report: Revenue and Ridership Potential in the San Francisco/Sacramento-Los Angeles Corridor Technical Appendix. University of California Transportation Center (UCTC) working paper \# 186, University of California at Berkeley

Vranich J (1993) Supertrains: Solution's to America's Transportation Gridlock. St. Martin's Press, New York

Wayson RL, Bowlby W (1989) Noise and Air Pollution of High Speed Rail Systems. ASCE Journal of Transportation Engineering 115(1):20-36 